\title{
HEALTH STATUS OF LONG-TERM SICK LEAVE AND WORKING FEMALE TEACHERS IN GERMANY: A CROSS-SECTIONAL STUDY
}

JULIA BRÜTTING ${ }^{1}$, DIANA DRUSCHKE ${ }^{2}$, SILVIA SPITZER ${ }^{3}$, and REINGARD SEIBT ${ }^{4}$

${ }^{1}$ Dresden University of Technology, Dresden, Germany

Skin Cancer Unit at the University Cancer Center Dresden, Faculty of Medicine Carl Gustav Carus, Department of Dermatology

${ }^{2}$ University Hospital of Dresden, Dresden, Germany

Centre for Evidence-based Health Care

${ }^{3}$ Dresden University of Technology, Dresden, Germany

Faculty of Medicine Carl Gustav Carus, Institute and Policlinics for Occupational and Social Medicine

${ }^{4}$ University of Rostock, Rostock, Germany

Institute of Preventive Medicine and Center for Life Science Automation

\begin{abstract}
Objectives: Limited research on the health situation of teachers on long-term sick leave is available. The aim of this study has been to describe the health status of female teachers on long-term sick leave (LSFT) in comparison to working female teachers (WFT) and to determine predictors for their state of mental health (MH) and cardiovascular fitness (CF). Material and Methods: Twenty-eight LSFT and 300 WFT (average age: $53 \pm 5$ years old) participated in a screening diagnostic inventory. Mental health, CF, blood pressure (BP), body mass index (BMI), body fat mass (BFM), health behavior (smoking, alcohol intake, physical activity) and disease burden (DB - number of medical diagnoses) were analyzed for the purpose of characterization of the health status. The multiple linear regression analysis was performed to identify predictors for the state of MH and CF. Results: Adverse values for the MH but also for CF, BFM and the DB (median of medical diagnoses: LSFT: 5; WFT: 2) among the LSFT in comparison to the WFT were confirmed. Additionally, the part of smokers among LSFT (25\%) was higher (WFT: $8 \%$ ). In contrast, the WFT (61\%) were much more affected by an elevated BP (LSFT: 26\%). Disease burden proved as the strongest predictor for MH of the female teachers. Age, BMI and DB proved as predictors for CF. Conclusions: Health-related differences between long-term sick leave and working teachers were particularized and a link between physical and mental health among teachers was quantified. Therefore, health-related concepts for teachers should equally focus on physical and psychological aspects. The relevance of regular well-structured occupational health check-ups should be brought to the attention of the profession to prevent diseases and early retirements. Int J Occup Med Environ Health 2018;31(2):227-242
\end{abstract}

Key words:

Mental health, Sickness absence, Cardiovascular risk factors, Teacher, Disease burden, Cardiovascular health

Funding: the data of the sample was collected as part of the project "In teaching profession healthy and motivated until retirement - ways of preventing and personnel development” („Im Lehrerberuf gesund und motiviert bis zur Rente - Wege der Prävention und Personalentwicklung”), project manager: Reingard Seibt, D.Sc. The project was funded by the German Statutory Accident Insurance (Deutsche Gesetzliche Unfallversicherung - DGVU) within the series "My next occupation - personnel development for occupations with limited duration of work” („Mein nächster Beruf - Personalentwicklung für Berufe mit begrenzter Tätigkeitsdauer”) (code FP 314). Received: August 29, 2016. Accepted: January 11, 2017.

Corresponding author: R. Seibt, University of Rostock, Institute of Preventive Medicine and Center for Life Science Automation (CELISCA), St.-Georg-Straße 108, 18055 Rostock, Germany (e-mail: reingard.seibt@uni-rostock.de). 


\section{INTRODUCTION}

In Germany 797000 people are primarily employed as teachers and about 30000 of them work in Saxony, one of 16 federal states. This population is the largest academic occupational group in which more than $70 \%$ are female [1]. In recent years, the health situation of teachers has repeatedly been the subject of public discussion. Reasons may be found in high numbers of early retirement due to illnesses [2] or the problem of aging in the profession [3]. Compared to other occupational groups teachers are more affected by mental and psychosomatic disorders [4,5]. These cause above average numbers of sick days in the population and are the main reasons for chronic illness and early retirement $[6,7]$. In 2000, $64 \%$ of teachers' retirements were due to health problems. Since the legal implementation of financial deductions in the same year, early retirement rates have been declining and are currently at $13 \%$. However, chronic illnesses and long-term sick leave are conversely rising especially in the eastern region of Germany $[7,8]$. Long-term sickness leave is defined as not being able to work for at least 42 days a year due to health problems. Between $4-5 \%$ of all illness cases in the German working population are affected annually and these cases cause up to $43 \%$ of all disability days [9]. On average $3.8 \%$ of German teachers dropped out for such a period of time in 2013 but the rates vary considerably among the federal states. In Saxony for example the rate increased from $2.8 \%$ to $5.1 \%$ between 2007-2012 [10]. Rates in some of the other German states, such as Berlin (2011: 5.8\%) [11] or Saxony-Anhalt (2013: 6.4\%) [7], are even higher.

Actually, German teachers have a better physical health status and show more beneficial behavioral patterns in comparison to the general population $[4,8]$. However, several analyses have also revealed variances for subgroups of the profession in health-related components, e.g., for principals and teacher [12], part- and fulltime employed teachers [13], sick and healthy teachers [14] or teachers of different school types [10]. But it has lacked empirical evidence for teachers on long-term sick leave so far.
In general, most findings on the health of teachers are based on subjective assessments. There is little evidence derived from objective data directly collected as part of physical examinations or tests [5,15]. Therefore one objective of this study has been to compare health status of long-term sick leave and working female teachers by focusing the mental and cardiovascular situation and using data of both subjective and objective quality as well [1]. Furthermore, it has been of particular interest whether relationships between mental and physical health components are detectable among teachers [2].

\section{MATERIAL AND METHODS}

\section{Sample}

The examination was carried out in the context of a preventive occupational-medical and psychological check-up conducted between September 2012 and December 2013. Working teachers were asked for participation in the study when having a preventive occupational-medical check-up. Teachers on long-term sick leave were recruited when staying in a mental health clinic during the same period.

We enrolled a total of 328 female teachers aged 40-60 years old for the study. At the time of the survey, 28 of them had been dropped out for long-term sick leave and 300 were active in their job (working population). Forty-one percent of the long-term sick leave and $71 \%$ of working teachers were employed part-time, working in a scope of $50-85 \%$ of the volume of a full-time employee.

In the baseline sample (more than 700 male and female teachers), female teachers made up $81.5 \%$. A small number of male teachers, male and female head teachers as well as student teachers were excluded from the analyses to improve the comparability (internal validity) of the study sample. Participation of the female working teachers corresponds to a response rate of $78 \%$. Out of the female teachers on longterm sick leave, all (100\% response) could be motivated to participate.

The calculation of the optimal sample sizes for each group was carried out by using the software $G^{*}$ Power 3 [16] and 
using a formula for finite populations. Based on a population of Saxon teachers $(\mathrm{N}=30000)$ and a prevalence of teachers on long-term sick leave of $3 \%$, a minimum needed sample size of $\mathrm{N}=24$ was calculated for each group (expecting a dropout of $10 \%$ and $\alpha=0.05$ ).

The average age of both female teacher groups did not differ significantly (mean age female teachers on long-term sick leave (LSFT): $53 \pm 7$ years old, working female teachers (WFT): $53 \pm 4$ years old). Median duration of longterm sick leave of participants was 4 months.

\section{Study design and instruments}

For the purpose of this ex-post-facto cross-sectional analysis, examination of the health status and the cardiovascular risk factors was carried out for all teachers in the sample. The data was collected as part of an extended occupational health screening based on the Dresden Model [17] - an occupational health screening developed and applied by the Institute and Policlinics for Occupational and Social Medicine of the Dresden University of Technology. This screening diagnostic inventory consists of teacher-specific occupational history, standardized questionnaires and medical measurements.

In addition common cardiovascular risk factors, components of health behavior and the self-reported current situation of disease burden were assessed for the purpose of the characterization of the physical health status. For the purpose of the sample description, socio-demographic data (e.g., age, marital status) and anamnestic factors were assessed. From the whole range of parameters collected according to the Dresden Model [17], the following health components were selected and analyzed in this study.

Mental health (MH): dependent variable 1

The state of mental health was assessed by using the (German) short version of the General Health Questionnaire-12 (GHQ-12) [18]. The GHQ-12 is a valid screening questionnaire for mental health problems and minor psychological impairments [19]. It is based on the self-reported state of general well-being in the previous 4 weeks. The symptoms are estimated according to a 4 step answering scale ("not at all," "same as usual," slightly more than usual" and "much more than usual") and evaluated by the classic GHQscoring [19] resulting in a sum score between 0 (mentally fit) and 12 (impaired in mental health). As a cut-off for impaired psychological health a GHQ-12 value $\geq 5$ was used, following Üstün and Sartorius [20].

\section{Cardiovascular fitness (CF): dependent variable 2}

The main measure for the physical health status was the cardiovascular fitness determined by the pulse performance index (PPI) [21]. For assessment purposes, the teachers completed 2 comparable submaximal stress tests - an ergometer and knee bends test. These tests included measurements of rest and stress pulse rates (bpm) and stress time (s). The stress pulse rate was measured directly after finishing the exercise. Given these measurements the PPI was calculated using the following formula [21]:

$$
\mathrm{PPI}=\frac{\text { stress pulse rate }(\mathrm{bpm})-\text { resting pulse rate }(\mathrm{bpm})}{\text { stress time }(\mathrm{s})}
$$

where:

PPI - pulse performance index.

A PPI of more than 1 corresponds to a good cardiovascular fitness (PPI $\geq 2$ is very good), a PPI of $\leq 1$ corresponds to bad fitness or inadequate training [22].

\section{Cardiovascular risk factors}

Elevated measures of the resting blood pressure (BP), the body mass index (BMI) and the body fat mass (BFM) were considered to be risk factors for cardiovascular diseases (for the standardized screening method see Seibt et al. [17]). Blood pressure and BMI were measured as part of the physical examination. The proportion of body fat mass was determined by applying the bioimpedance analysis [23] and 
was presented in terms of percent. For the purpose of classification of determined body fat values we used established age-related reference values published elsewhere [24].

Health behavior

Health behavior (sports, smoking, alcohol consumption) and socio-demographic data were assessed by means of a self-reported medical history [25].

\section{Disease burden (DB)}

Information about the disease burden has been obtained by applying subscale 3 of the Work Ability Index (German version [26]). The questionnaire asks for 14 diverse groups of diseases. Within every group, several diagnoses are summarized. One group sums up psychological disorders, the remaining 13 groups summarize different physical diseases. Participants had to specify whether a diagnosis existed or not. The current number and the kind of diseases diagnosed by a physician have been considered in the evaluation.

\section{Ethics}

All teachers were informed about the study's aims and methods and gave their written informed consents. There was the possibility to terminate participation without any consequences at any time during the duration of the study. All procedures performed in this study involving human participants were in accordance with the ethical standards of the institutional research committee and with the 1964 Helsinki Declaration and its later amendments or comparable ethical standards. The necessary ethics committee approval was provided by the Education Agency of Saxony (Sächsische Bildungsagentur; file reference: ZS-6499.20/789/1, August 7, 2012).

\section{Statistics}

The statistical analysis was performed as uni- and multivariate one using commercially available software
(SPSS for Windows, release 20.0). Descriptive analyses included means and standard deviations or medians and 25 th/75th quantiles for quantitative measures and percentages for categorical variables. Normal distribution was assessed by inspecting skewness and kurtosis of the respective residuals (normal distribution: -1 and +1 ) as well as by considering the results of the Kolmogorov fitness test. In comparative analyses the parametric t-test or Welsh-test were applied for normal distributed data. Non-normally distributed data was analyzed by non-parametric $U$ test according to Mann-Whitney. For categorical data the $\mathrm{Chi}^{2}$ test was used. Additionally, we determined effect size d according to Cohen [27] to estimate magnitude of differences between the teacher groups. Values of $d$ may be grouped as follows: $0.2<\mathrm{d} \leq 0.4=$ small effect; $0.4<\mathrm{d} \leq 0.7=$ medium effect; $0.7<\mathrm{d}=$ strong effect.

The state of mental health and cardiovascular fitness were considered as dependent variables for the purpose of the multivariate analysis. Multiple linear regression analyses were applied for determination of potential predictors for mental health and cardiovascular fitness. We conducted 2 separate regression analyses: first, the aim was to determine predictors of mental health status. Then, the predictors of cardiovascular fitness were determined.

In both cases 2 steps were done. At first, each cardiovascular risk factor was tested as a possible predictor for each dependent variable. Then components of health behavior, the number of medical diagnoses, the age of teachers and the relevance of part-time employment were tested in the same way. As the second step, all predictive components that had proven to be significant $(\mathrm{p}<0.05)$ in the first step were analyzed in a combined model for each dependent variable by backward selection process. To qualify all data for this statistical method, GHQ-12 score data was logarithmically transformed to get normal distribution, to fulfill all prerequisites and not to lose any data integrity. 


\section{RESULTS}

\section{Comparison between long-term sick leave and working female teachers}

Mental health

As expected, from the fact that the teachers on longterm sick leave were recruited in a mental health clinic, both female teacher groups differed significantly in terms of the state of mental health (Table 1): whereas the median GHQ-12 sum score among the LSFT was 7, it was 1 in the WFT sample. Higher GHQ-12 sum scores indicated a general mental impairment. Accordingly, $86 \%$ of LSFT and $27 \%$ of the WFT in our sample could be assumed as psychologically impaired ( $\geq 5$ points) [20].

\section{Cardiovascular fitness (CF)}

Given an average PPI value of 1.2 among the LSFT and a value of 1.7 among the WFT (Table 1), the overall cardiovascular fitness in both groups was good (PPI values $\geq 1$ and $\leq 2$ ) and may be regarded as positive but the detected difference was statistically significant. Following Meißner-Pöthig [22] the cardiovascular fitness of $36 \%$ in the WFT and $29 \%$ in the LSFT sample had to be classified as bad. Another glance at the distribution of PPI values $\geq 2$ revealed that $27 \%$ of the WFT had a very good cardiovascular fitness whereas none of the LSFT were able to reach equivalent values.

\section{Cardiovascular risk factors}

As cardiovascular risk factors, the blood pressure (BP), body measurements (BMI, body fat mass) and the selfreported health behavior were assessed.

\section{Body measurements}

According to the European Society of Hypertension [28], the average systolic blood pressure (SBP) values in both teacher groups (LSFT: $130 \pm 12 \mathrm{~mm} \mathrm{Hg}$; WFT: $136 \pm 17 \mathrm{~mm} \mathrm{Hg}$ ) were within the normal range (Table 2). The average diastolic blood pressure (DBP) value of

Table 1. Health status of long-term sick leave female teachers (LSFT) and working female teachers (WFT), September 2012 - December 2013, Germany

\begin{tabular}{|c|c|c|c|c|c|}
\hline \multirow{2}{*}{ Response variable } & \multicolumn{2}{|c|}{$\begin{array}{l}\text { Study group } \\
(\mathrm{N}=328)\end{array}$} & \multicolumn{3}{|c|}{ Significance } \\
\hline & $\begin{array}{c}\text { LSFT } \\
(\mathrm{N}=28)\end{array}$ & $\begin{array}{c}\text { WFT } \\
(\mathrm{N}=300)\end{array}$ & test statistics & $\mathrm{p}$ & ES \\
\hline \multicolumn{6}{|l|}{ Mental health } \\
\hline GHQ-12 score $(0-12)^{\mathrm{a}}(\mathrm{Me}(25-75$ th percentile $))$ & $7(5-11)$ & $1(0-4)$ & $\mathrm{U}=1436.00$ & $<0.001^{* * *}$ & 1.75 \\
\hline impaired mental health ${ }^{\mathrm{b}}[\%]$ & 85.7 & 27.3 & $\mathrm{Chi}^{2}=39.91$ & $<0.001^{* * *}$ & 0.74 \\
\hline Cardiovascular fitness (PPI) [\%] (M $\pm \mathrm{SD})$ & $1.2 \pm 0.5$ & $1.7 \pm 0.7$ & $\mathrm{t}=4.30$ & $<0.001^{* * *}$ & 0.73 \\
\hline$\leq 1$ (poor) $[\%]$ & 36.0 & 29.0 & $\mathrm{Chi}^{2}=10.21$ & $0.006^{* *}$ & 0.36 \\
\hline$\geq 2$ (very good) $[\%]$ & 0.0 & 27.0 & & & \\
\hline
\end{tabular}

a Scale for mental health status (GHQ-12 - General Health Questionnaire-12 [18]).

${ }^{b}$ Range of GHQ score values: higher values indicate a poorer mental health status; classification of impairment of mental health (cases) by the cut-off $\geq 5$ points.

PPI - pulse performance index: stress pulse rate $[\mathrm{bpm}]=$ resting pulse rate $[\mathrm{bpm}] /$ stress time $[\mathrm{s}](\mathrm{PPI} \geq 2$ - very good cardiovascular fitness; PPI $\leq 1$ - bad cardiovascular fitness or inadequate training) [22].

$\mathrm{Me}$ - median; M - mean; SD - standard deviation.

ES - d effect size [27]; U - Mann-Whitney U test; $\mathrm{Chi}^{2}$ - frequencies, $\mathrm{Chi}^{2}$ test (Pearson); $\mathrm{t}$ - paired two-sample $\mathrm{t}$ test.

Significance (two-tailed): ${ }^{* * *} \mathrm{p}<0.001 ; * * \mathrm{p}<0.01{ }^{*} \mathrm{p}<0.05$. 
the LSFT $(82 \pm 9 \mathrm{~mm} \mathrm{Hg})$ may also be regarded as normal whereas the one in the WFT sample $(92 \pm 11 \mathrm{~mm} \mathrm{Hg})$ has to be classified as elevated. All in all $26 \%$ of the LSFT and $61 \%$ of the WFT are effected by elevated blood pressure values and mean differences between the groups prove to be significant.
The body mass index did not differ significantly between the 2 groups but the average values $\geq 25 \mathrm{~kg} / \mathrm{m}^{2}$ were alarming (Table 2): $64 \%$ of the LSFT and $51 \%$ of the WFT were overweight or even obese.

Values of body fat mass differed significantly in favor of the WFT (LSFT: 38\%; WFT: 34\%). Age-dependent el-

Table 2. Cardiovascular risk factors and disease burden of long-term sick leave female teachers (LSFT) and working female teachers (WFT), September 2012 - December 2013, Germany

\begin{tabular}{|c|c|c|c|c|c|}
\hline \multirow{2}{*}{$\begin{array}{l}\text { Cardiovascular risk factor / } \\
\text { Disease burden }\end{array}$} & \multicolumn{2}{|c|}{$\begin{array}{l}\text { Study group } \\
(\mathrm{N}=328)\end{array}$} & \multicolumn{3}{|c|}{ Significance } \\
\hline & $\begin{array}{c}\text { LSFT } \\
(\mathrm{N}=28)\end{array}$ & $\begin{array}{c}\text { WFT } \\
(\mathrm{N}=300)\end{array}$ & test statistics & $\mathrm{p}$ & ES \\
\hline \multicolumn{6}{|l|}{ Body measurements } \\
\hline \multicolumn{6}{|l|}{ blood pressure (BP) } \\
\hline systolic [mm Hg] $(\mathrm{M} \pm \mathrm{SD})$ & $130.3 \pm 12.4$ & $135.6 \pm 17.1$ & $\mathrm{t}=2.17$ & $0.031^{*}$ & 0.36 \\
\hline diastolic $[\mathrm{mm} \mathrm{Hg}](\mathrm{M} \pm \mathrm{SD})$ & $82.0 \pm 9.4$ & $91.8 \pm 11.2$ & $\mathrm{t}=4.80$ & $<0.001^{* * *}$ & 0.90 \\
\hline hypertensive values ${ }^{\mathrm{a}}[\%]$ & 26 & 61 & $\mathrm{Chi}^{2}=12.52$ & $<0.001 * * *$ & 0.40 \\
\hline antihypertensive medication [\%] & 46 & 29 & $\mathrm{Chi}^{2}=4.11$ & $0.043^{*}$ & 0.23 \\
\hline body mass index $(\mathrm{BMI})\left[\mathrm{kg} / \mathrm{m}^{2}\right](\mathrm{M} \pm \mathrm{SD})$ & $28.7 \pm 6.3$ & $25.9 \pm 4.2$ & $\mathrm{t}=-1.55$ & 0.133 & 0.64 \\
\hline overweight $(\mathrm{BMI} \geq 25)^{\mathrm{a}}[\%]$ & 64 & 51 & $\mathrm{Chi}^{2}=1.81$ & 0.235 & 0.15 \\
\hline obesity $(\mathrm{BMI} \geq 30)^{\mathrm{a}}[\%]$ & 25 & 15 & $\mathrm{Chi}^{2}=11.29$ & 0.095 & 0.38 \\
\hline body fat mass [\%] (Me (25-75th percentile)) & $38(33-45)$ & $34(30-38)$ & $\mathrm{U}=2826.0$ & $0.01^{*}$ & 0.68 \\
\hline elevated body fat mass $(>26 \%)^{b}[\%]$ & 79 & 67 & $\mathrm{Chi}^{2}=1.494$ & 0.222 & 0.14 \\
\hline \multicolumn{6}{|l|}{$\begin{array}{l}\text { Health behavior } \\
\text { smoking }^{c}\end{array}$} \\
\hline smokers [\%] & 25 & 8 & $\mathrm{Chi}^{2}=8.65$ & $0.01^{*}$ & 0.34 \\
\hline cigarettes [n/day] $(\mathrm{M} \pm \mathrm{SD})$ & $9.8 \pm 8.4$ & $8.3 \pm 6.2$ & $\mathrm{t}=-0.95$ & 0.925 & 0.23 \\
\hline \multicolumn{6}{|l|}{ alcohol intake } \\
\hline never/sometimes [\%] & 93 & 97 & $\mathrm{Chi}^{2}=4.02$ & 0.080 & 0.22 \\
\hline regular $[\%]$ & 7 & 3 & & & \\
\hline glasses [n/week] (Me (25-75th percentile)) & $1.8(0.0-3.0)$ & $2.0(1.0-4.0)$ & $\mathrm{U}=3068.00$ & 0.158 & 0.11 \\
\hline \multicolumn{6}{|l|}{ sports } \\
\hline no/rare $[\%]$ & 11 & 23 & $\mathrm{Chi}^{2}=3.60$ & 0.451 & 0.21 \\
\hline once to 3 times/week [\%] & 81 & 69 & & & \\
\hline everyday [\%] & 7 & 8 & & & \\
\hline h/week (Me (25-75th percentile)) & $2.0(2.0-3.0)$ & $2.8(1.0-4.0)$ & $\mathrm{U}=2717.0$ & 0.203 & 0.29 \\
\hline physically active ( $\geq 2.5 \mathrm{~h} /$ week $)^{\mathrm{d}}[\%]$ & 35 & 52 & $\mathrm{Chi}^{2}=2.85$ & 0.091 & 0.19 \\
\hline
\end{tabular}


Table 2. Cardiovascular risk factors and disease burden of long-term sick leave female teachers (LSFT) and working female teachers (WFT), September 2012 - December 2013, Germany - cont.

\begin{tabular}{|c|c|c|c|c|c|}
\hline \multirow{2}{*}{$\begin{array}{l}\text { Cardiovascular risk factor / } \\
\text { Disease burden }\end{array}$} & \multicolumn{2}{|c|}{$\begin{array}{l}\text { Study group } \\
(\mathrm{N}=328)\end{array}$} & \multicolumn{3}{|c|}{ Significance } \\
\hline & $\begin{array}{c}\text { LSFT } \\
(\mathrm{N}=28)\end{array}$ & $\begin{array}{c}\text { WFT } \\
(\mathrm{N}=300)\end{array}$ & test statistics & $\mathrm{p}$ & ES \\
\hline \multicolumn{6}{|l|}{ Disease burden (WAI 3) } \\
\hline medical diagnoses [n] $(\mathrm{Me}$ (25-75th percentile) $)$ & $5(3-7)$ & $2(1-3)$ & $\mathrm{U}=1533.5$ & $<0.001^{* * *}$ & 1.40 \\
\hline$<2$ diagnoses [\%] & 0 & 41 & $\mathrm{Chi}^{2}=34.77$ & $<0.001^{* * *}$ & 0.69 \\
\hline$\geq 2$ diagnoses [\%] & 100 & 59 & & & \\
\hline \multicolumn{6}{|l|}{ morbidity structure (main medical diagnoses) [\%] } \\
\hline mental & 82 & 15 & $\mathrm{Chi}^{2}=68.82$ & $<0.001^{* * *}$ & 1.03 \\
\hline musculoskeletal & 86 & 43 & $\mathrm{Chi}^{2}=19.09$ & $<0.001^{* * *}$ & 0.50 \\
\hline hormonal and metabolic system & 46 & 15 & $\mathrm{Chi}^{2}=18.00$ & $<0.001^{* * *}$ & 0.48 \\
\hline nerves and senses & 39 & 18 & $\mathrm{Chi}^{2}=7.30$ & $0.007^{* *}$ & 0.30 \\
\hline accidental injuries & 36 & 19 & $\mathrm{Chi}^{2}=4.18$ & $0.041^{*}$ & 0.23 \\
\hline cardiovascular & 36 & 31 & $\mathrm{Chi}^{2}=0.31$ & 0.581 & 0.06 \\
\hline gastrointestinal & 29 & 16 & $\mathrm{Chi}^{2}=3.06$ & 0.080 & 0.19 \\
\hline
\end{tabular}

${ }^{a}$ European Guidelines for the Treatment of Arterial Hypertension [28].

${ }^{\mathrm{b}}$ Body composition [23].

${ }^{c}$ Questionnaire of Occupational and Medical History [25].

${ }^{\mathrm{d}}$ WHO 2010 [29].

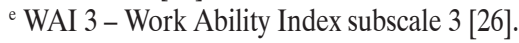

Other abbreviations and explanations as in Table 1.

evated values of body fat mass were measured in $79 \%$ of the LSFT and $67 \%$ of the WFT (Table 2).

\section{Health behavior}

Apart from the smoking pattern, LSFT and WFT showed comparable expressions in health behavior (Table 2). At time of examination, $25 \%$ of the LSFT and $8 \%$ of the WFT reported to be active smokers. This difference proved to be significant. Seven percent of the LSFT and $3 \%$ of the WFT regularly consumed alcohol, the other female teachers reported to drink sporadic or never. Sixty-nine percent of the LSFT and $82 \%$ of the WFT reported physical activities one to 3 times a week (i.e., participating in sports or exercising). On average LSFT were physically active for $2.2 \mathrm{~h} /$ week and WFT for $2.8 \mathrm{~h}$. Following the categorization of the World Health Organization (WHO) [29] 35\% of the LSFT and 52\% of the WFT could be classified as physically active by exercising sports for at least $2.5 \mathrm{~h} /$ week.

\section{Disease burden}

On average, the LSFT reported 5 and the WFT 2 medical diagnoses (Table 2). This difference in disease burden proved to be significant $(\mathrm{p}<0.001)$. Additionally, it should be mentioned that all of the LSFT in our sample reported to have at least 2 medical diagnoses whereas $41 \%$ of the WFT were affected by only one or none. In addition to psychological disorders, LSFT were most and significantly 
more frequently affected than WFT by musculoskeletal, hormonal and metabolic disorders, neuronal or sensory disorders as well as accidental injuries (Table 2). There was no significant difference in the expression of cardiovascular diseases and the other diagnostic groups.

\section{Predictors for mental health}

\section{and cardiovascular fitness}

Data exploration in advance of multivariate analyses revealed a widespread distribution of data in some variables and in both teacher groups. In order to make statements for female teachers concerning single components, final regression analyses were carried out for the whole sample and not separately for each teacher group.

Multiple linear regression analyses were applied to test the influence of the examined factors on the state of mental health and the cardiovascular fitness. In the combined
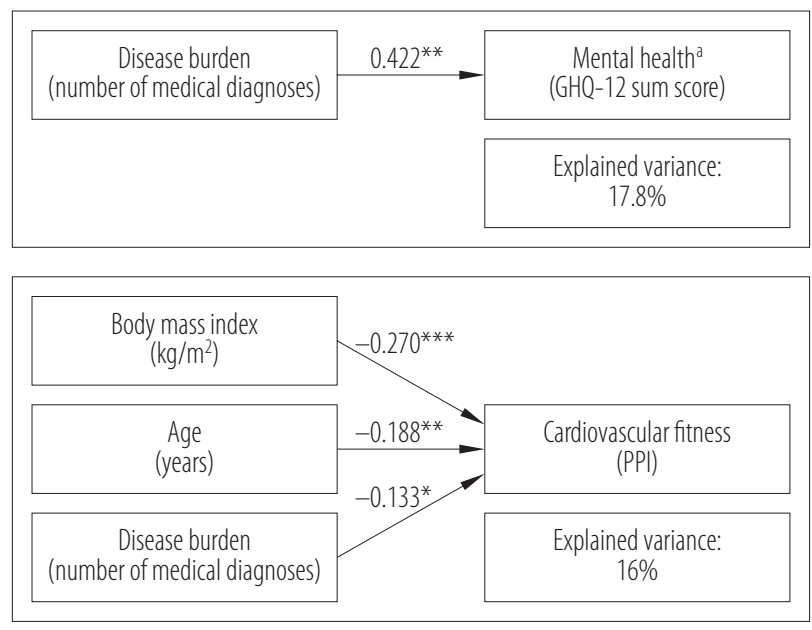

${ }^{a}$ GHQ-12 sum score logarithmic converted to linearize the data and fulfill condition for multiple linear regression.

GHQ-12 - General Health Questionnaire-12 [18]; PPI - pulse performance index.

Significance (two-tailed): ${ }^{* * *} \mathrm{p}<0.001 ;{ }^{* *} \mathrm{p}<0.01 ;{ }^{*} \mathrm{p}<0.05$.

Fig. 1. Predictors of mental health and cardiovascular fitness (multiple linear regression model: beta-coefficients) among the long-term sick leave female teachers $(\mathrm{N}=28)$ and working female teachers $(\mathrm{N}=300)$, September 2012 - December 2013, Germany model (Figure 1) solely the number of disease burden (medical diagnoses) proved to be a relevant predictor of the mental health status of the female teachers and elucidated a variance proportion of $18 \%\left(\mathrm{R}^{2}=0.178\right)$.

For prediction of the female teachers' cardiovascular fitness (Figure 1), BMI, age and disease burden proved to be relevant. All of these components explained a variance proportion of $16 \%\left(\mathrm{R}^{2}=0.160\right)$ in the finale combined model. In both analyses, the scope of employment (parttime vs. full-time) was not significantly predictive.

\section{DISCUSSION}

The teaching profession has been labeled as highly stressful $[30,31]$ and such exposure may elevate the risk for mental and physical health problems [32,33]. Moreover relationships between mental and physical health components have already been investigated and demonstrated on several occasions [34]. Such relationships are suspected even with teachers [2] but have hardly been investigated [5]. In particular for ill teachers only few results exist to describe their health situation in more detail and even fewer results exist for teachers on long-term sick leave. The fact that the German teacher population is inter alia affected by aging demands a coincident analysis of the mental and physical health situation to get an overview and in order to find suitable solutions in terms of preventive and intervening measures for this occupational group. Against this background we have examined and compared the state of mental health and the cardiovascular fitness among 300 working female teachers and 28 female teachers on long-term sick leave as a first step. As a second step we have determined predictors for the state of mental health and for the cardiovascular fitness among all measured components.

\section{Considered components of health status}

In summary our investigation confirms fundamental differences between female teachers on long-term sick leave and working female teachers in the expression of selected 
health components. We have identified the disease burden as predictor for both, the state of mental health and the cardiovascular fitness have confirmed the relevance of age and BMI for the cardiovascular fitness. But as demonstrated previously [13], regression analyses have revealed no significant relevance of the scope of employment for considered health components.

\section{Mental health status}

In the sample of female teachers on long-term sick leave $86 \%$ showed signs of mental impairment (GHQ-12 sum score $\geq 5$ ). Because of clinical diagnoses and the fact that participants were selected from a mental health clinic such a high rate was expected. Independent from this result, mental impairment is the main reason for long-term sick leave among German teachers, especially among females [7,35]. Also for $27 \%$ of the working female teachers in our sample, mental health problems may be suspected. This proportion is slightly higher than in the study by Seibt et al. [4] but scores are comparable with the results of another study [13] that also used GHQ-12 as the screening instrument and had the same cut-off. In comparison: Among German women about one third $(33 \%)$ suffer from a mental disorder annually [35]. Accordingly, the proportion of working female teachers in our sample who stated to feel mentally impaired was slightly lower compared with German women in the general population. Using the cut-off value of $\geq 4$, Bauer et al. [36] found $29 \%$ of female teachers showed signs of significant mental health problems. They also identified that the GHQ-12 score did not differ significantly across gender and age-range. In addition, Goldberg et al. [19] demonstrated that GHQ values varied between populations and countries. Another GHQ-12 validity study revealed an equally wide range of best estimates for threshold scores ranging from $0 / 1$ to $5 / 6$, but the variation in best thresholds was unaccounted for [37]. Gender, age and educational level were also shown to have no significant effect on the validity of GHQ values [19]. Our findings confirm a missing correlation between GHQ score and age $(\mathrm{r}=0.08)$, too.

\section{Cardiovascular fitness status}

On average the female teachers, who were examined, were of favorable cardiovascular fitness. However, differences between both groups became visible through categorical classifications [22]. Whereas $27 \%$ of the working female teachers reached values corresponding to having very good cardiovascular fitness, none of the ones on long-term sick leave were able to perform that way. In return, more women in the sample on long-term sick leave had poor cardiovascular capacity. Indirectly, these findings have been confirmed by results of a teacher study carried out by Döring-Seipel and Dauber [14]. There, ill teachers also reported greater physical limitations than their healthy counterparts.

However, because of numerous limitations a direct comparison of these study results is not recommended. Further investigations of teachers on long-term sick leave and more frequent objective measurement of the cardiovascular fitness are desirable. To date, the results certify a better physical fitness for working teachers in comparison to the general population $[4,38]$.

\section{Cardiovascular risk factors}

Interestingly, our results for resting blood pressure have indicated that the teachers on long-term sick leave $(26 \%)$ are significantly less affected by elevated (hypertensive) values than their working colleagues (61\%). But at the same time they are treated more frequently by antihypertensives. On the one hand this could explain the significant blood pressure differences. On the other hand it could be a result from the continuing influence of further exposure to work stress at the WFT as previously shown [39]. To the authors' knowledge, differences in the blood pressure between long-term sick and working female teachers have not yet been studied, taking into account the meaning of 
work-related characteristics and working stress. Recent literature also suggests that working teachers are more often affected by hypertension as compared to the general population $[4,38]$.

In another Saxon teacher sample $(\mathrm{N}=2156)$, elevated blood pressure values were measured for $60 \%$ of participants [4], too. A total of $30 \%$ among German women and $35 \%$ in the group of women at the age of 50-59 years old were affected by an elevated blood pressure or hypertension [40]. Despite the significant difference between the 2 examined teacher groups, mean values of both groups were well above those of the female German population. More than $50 \%$ of the examined female teachers in both groups were overweight. Obesity was especially associated with a higher cardiovascular risk [28]. In Germany $53 \%$ of the women and in the group of those 50-59 year old $61 \%$ were affected by overweight [41].

Compared to this data, the working teachers involved in our study, showed a lower degree of overweight whereas the teachers on long-term sick leave were more affected. Our findings are consistent with previous results for distribution of obesity among teachers: even those certify a lesser concern for working teachers compared to the general population $[4,8]$. However, there is still a need for examination into the severity of obesity and other components used for description of the metabolic state of chronically ill teachers in order to put our results into consideration and to evaluate potential regional differences. General population studies provide indications of some differences between regions and within gender groups [42].

In both groups the mean proportion of body fat was above $30 \%$. Seventy-nine percent of the female teachers on long-term sick leave and $67 \%$ of the working female teachers were affected by elevated body fat mass proportion. These findings are in contrast to results by Seibt et al. [13]. There, $73 \%$ of the examined working female teachers $(\mathrm{N}=630$, mean age: 48 years $)$ were af- fected by an elevated body fat pattern with an average body fat composition of $23 \%$. Comparable results for teachers on long-term sick leave and the German general population were not available at submission date.

\section{Health behavior}

Compared with the German general female population, health behavior of the examined female teachers may be described as more positive. On average $27 \%$ of German women are smokers and only $16 \%$ are physically active according to the classification of the WHO [29]. In both components the female teachers in our sample reported better results. These findings are confirmed by previous results $[4,8]$.

However, compared to the general population, the female teachers in our sample consumed more alcohol: whereas $25 \%$ of German women did not consume alcohol, only $14 \%$ of the female teachers on long-term sick leave and $6 \%$ of the working female teachers reported no alcohol intake. Döring-Seipel and Dauber [14] reported a higher consumption of cigarettes and alcohol among ill teachers compared to their working colleagues. These findings may be confirmed by our results but the difference in alcohol consumption was not statistically significant.

Despite that they were less often smokers and more often physically active than their diseased colleagues, working teachers in our sample had a higher blood pressure level. This contradicts previous findings of a relationship between blood pressure and such health behavior components [43]. Since no significant difference in the physical activity could be identified between the 2 teacher groups, blood pressure differences cannot primarily be attributed to the sports variable.

It might be beneficial to additionally consider the kinds of practiced sporting activities in further studies, since different sports, for example weight lifting and endurance training have different effects on the cardiovascular system and blood pressure [44]. However, a dose- 
response relationship between job stress and high blood pressure is known from occupational and epidemiological studies [39]. We only can assume that blood pressure differences may be attributed to the existing work stress exposure of the working sample, while the teachers on long-term sick leave have not been affected thereby for months. This context should also be the subject of further investigations.

\section{Disease burden}

Generally, the number of diseases rises with age [45]. Because of an average age of $53 \pm 5$ years old in our sample an elevated mean number of diagnoses (chronic diseases) could be expected from the outset. However, the differences in burden disease between the female teachers on long-term sick leave and working female teachers were remarkable. By 5 diagnoses on average the ill female teachers suffered a disease burden that was more than twice as high as that of their working colleagues. Results from current literature confirm our findings for the working sample $[8,13]$ but again it lacks evidence for teachers on long-term sick leave. Looking at the morbidity structure, order of disease groups in the working teachers is similar to the general population [46]: musculoskeletal and cardiovascular disorders are the main physical health problems $[8,46]$.

\section{Predictors for the mental health status and cardiovascular fitness}

The multiple linear regression analysis of potential predictors identified the disease burden as the sole and strongest predictor (variance explanation: 18\%) for the mental health status of the female teachers. This indicates a particularly large impact of the variable. By contrast, the examined cardiovascular risk factors, health behavior and the scope of employment (part-time vs. full-time) proved to be a little or no relevance for the state of mental health. This is confirmed for working as well as for part-time and full-time employed female teachers by Seibt et al. [13] but contradicts findings that confirm a relationship between cardiovascular and mental health [47,48].

Explaining a variance of $16 \%$, BMI, age and disease burden proved to be relevant predictors for the cardiovascular fitness in our sample. If disease burden is not taken into account, age and BMI still clarify a variance of $14 \%$. Thus, disease burden plays a much lower role for the cardiovascular fitness of the female teachers than for their mental health situation.

Further studies $[49,50]$ confirm the relevance of age and body weight for cardiovascular performance and health [51] although cardiovascular outcome variables where characterized and described differently. However, the relevance of disease burden and its amount on cardiovascular fitness and mental health status has been sparsely studied up to now. So far, disease burden has been of greater interest in context of the quality of life [52].

\section{Limitations of the study}

The interpretation of our results is limited by characteristics of the cross-sectional design. It is impossible to determine the causal direction of effects between the mental health state and physical health variables. Additionally, voluntary participation in the study causes that conditions for a random sample were not given. This is consequently associated with the selection processes. It is possible that there were either more health-conscious and healthier or more disabled participants in the sample. In this context the healthy worker effect might be observed - a methodological problem arising from the fact that severely impaired teachers have already retired and therefore could not be analyzed.

In consequence the description of the health status might have been more positive than it actually was. Due to the low number of male teachers in the study population, we found it valid to limit the study sample to female teachers. However, this makes it more difficult to generalize 
the results. For example, relevant gender differences of health indicators could not be examined.

The limitations of representativeness might be also caused by the fact that the teacher sample was a regional sample from the area of Saxony, Germany. Therefore, this study sample cannot be considered to be representative of all German teachers. In Germany, teacher recruitment and education is organized differently in several states. Thus, extrapolations must be made with caution. Furthermore, the limitations of the instruments used must be considered: the data in the used questionnaires (GHQ-12, Work Ability Index, health behavior) is based on self-reports which may be biased by effects of social desirability.

According to the GHQ-12 questionnaire, the literature mentions diverse cut-offs for the identification of cases, and cut-offs usually vary in diverse studies ranging 4-6 [53], depending on the evaluation strategy. For the measurement and evaluation of objective physical indicators, various common restrictions also have to be taken into account.

At first it should be noted that expressions of values may vary with daytime, the mental and physical condition of a person or consumption of stimulants (e.g., tobacco, coffee). These concerns are particular to the cardiovascular fitness and blood pressure. Secondly, the survey situation is special to the participants so the occurrence of the white coat effect [54] in the data might be possible. Up to $25 \%$ of the female teachers could have been affected by hypertensive blood pressure because of the presence of medical personnel. Based on the twice measured blood pressure values the presence of hypertension disease cannot be concluded. For medical diagnosis several repeated measurements are needed $[28,40]$. Only a situational overview of the resting blood pressure may be given.

Because of the mentioned possible biases, the results should be interpreted with caution and final conclusion concerning the state of health among female teachers cannot be drawn.

\section{CONCLUSIONS}

Health-related differences between long-term sick leave and working teachers were particularized and a link between mental and physical health among teachers was quantified. We have indicated that teachers on long-term sick leave are not only mentally impaired to a greater extent compared to their working colleagues but also physically. By this we have highlighted special health problems of another teacher subgroup. Even for the working female teachers the expression of problematic health components such as mental impairment, overweight, elevated body fat mass and elevated blood pressure have been determined. Now, 3 aspects may be derived from our and previous findings in terms of health-related concepts for teachers.

First, the particularities of the profession's internal subgroups should be considered and focused more intensively. Secondly, periodic and holistic monitoring of the health situation of all teachers with an equally intense look on mental and physical components should be established - especially against the background of aging in the profession and associated increased health risks. Thirdly, a comprehensive and long-term implementation of suitable programs has the potential to provide scientific evidence for further development of subgroup oriented health promotion interventions. The long-term goal should be to reduce long-term sickness leave and early retirement rates by considering special characteristics of the teaching profession even more to use them as starting points for intervention.

For that challenge, the Dresden Model [17], already established in Saxon, and its long-term implementation may be seen as an appropriate approach. It has a salutogenetic base and considers various health-related dimensions. As a primary-preventive instrument it offers an evidence based on occupational-medical health program with individual counselling and interdisciplinary cooperation of physicians and psychologists. But this model does not contain an expert-guided intervention program with respect to psychological problems. An approach focusing on protection of mental health 
of teachers by targeting stress and depression is the Freiburg Model [55], a well-accepted coaching and prevention program. The effectivity of this 10 -session-program was proven as intervention within a randomized controlled trial.

\section{ACKNOWLEDGMENTS}

We thank all the teachers who voluntarily participated in this research project and we would like to thank the German Statutory Accident Insurance (Deutsche Gesetzliche Unfallversicherung - DGVU) for support.

\section{REFERENCES}

1. Statistical Offices of the German Federation and the Federal States [Internet]. Wiesbaden: The Offices; 2016 [cited 2016 Mar 22]. [Education - Teachers in general schools listed by volume of employment and gender]. Available from: http://www. statistik-portal.de/Statistik-Portal/de_jb04_jahrtab24sch.asp. German.

2. Hundeloh H. [Health management at schools: Prevention and health promotion as tasks of school management]. Weinheim: Beltz; 2012. German.

3. Statistical Office Saxony [Internet]. Kamenz: The Office [cited 2016 Mar 22]. [Statistically speaking. Education in Saxony 2014]. Available from: https://www.statistik.sachsen.de/download/300_Voe-Faltblatt/SB_Bildung_2014.pdf. German.

4. Seibt R, Steputat A, Ulbricht S, Rehm U, Scheuch K. [Occupational-medical examinations: Report on the health situation of teachers of the Saxon Education Agency in 2010]. Chemnitz: Sächsische Bildungsagentur; 2011. German.

5. Nieskens B, Rupprecht S, Erbring S. [What keeps teachers fit? Results of health research for teachers and schools]. In: DAK-Gesundheit \& Unfallkasse NRW, editor. [Manual teachers health. Impetus to the development of good healthy schools]. Cologne: Carl Link; 2012. p. 41-96. German.

6. Schmitz E, Jehle P. [Internal resignation and early retirement among teachers]. In: Rothland M, editor. [Stress and strain in the teaching profession]. Wiesbaden: Springer; 2013. p. 15574. German.
7. Scientific Institute of the AOK. [Sickness of AOK-insured teachers at general schools in Germany in 2012 and 2013 A special evaluation]. Berlin: AOK; 2014. German.

8. Scheuch K, Haufe E, Seibt R. Teachers' health. Dtsch Ärzteblatt Int. 2015;112(20):347-56, https://doi.org/10.3238/ arztebl.2015.0347.

9. Meyer M, Böttcher M, Glushanok I. [Sickness absence in the German economy in 2014]. In: Badura B, Ducki A, Schröder H, Klose J, Meyer M, editors. [Absenteeism Report 2015] [Internet]. Berlin, Heidelberg: Springer; 2015. p. 341-548 [cited 2016 Mar 24]. Available from: https://doi. org/10.1007/978-3-662-47264-4. German.

10. Ulbricht S, Seibt R. [Report on mathematical and statistical analysis of data on occupational integration management (BEM) Saxon teachers for the school years 2007/08 to 2011/12]. Dresden: Publishing company of the Technical University Dresden; 2013. German.

11. House of Representatives Berlin. [Small question by Mr Özcan Mutlu (GREEN) from march 30, 2012. Cancellation of classes II. Printed Matter 17/10400]. Berlin: The House; 2012. German.

12. Seibt R, Spitzer S, Scheuch K. [Correlations between working capacity, stress and health at principals and teachers in primary schools] [Internet]. Dresden: Publishing company of the Technical University Dresden; 2009 [cited 2016 Mar 24]. Available from: http://zags-dresden.de/dateien/ZentrumLehrberufe/Seibt, R._Zusammenhang..._2009.pdf. German.

13. Seibt R, Matz A, Hegewald J, Spitzer S. Working conditions of female part-time and full-time teachers in relation to health status. Int Arch Occup Environ Health. 2012;85(6):675-87, https://doi.org/10.1007/s00420-011-0715-7.

14. Döring-Seipel E, Dauber H. [What teachers keeps fit: Empirical results on the importance of psychosocial resources in the teaching profession]. Göttingen: Vandenhoeck \& Ruprecht; 2013. German.

15. Matz A. [Predictors of mental health, depending on the volume of employment of Saxon teachers]. Dresden: Dresden University of Technology; 2013. German. 
16. Faul F, Erdfelder E, Lang A-G, Buchner A. G*Power 3: A flexible statistical power analysis program for the social, behavioral, and biomedical sciences. Behav Res Methods. 2007;39(2):175-91, https://doi.org/10.3758/BF03193146.

17. Seibt R, Druschke D, Hübler A, Scheuch K. [Guideline for individual preventive occupational-medical and psychological check-up among teachers. The Dresden Model]. Dresden: Publishing company of the Technical University Dresden; 2007. German.

18. Linden M, Maier W, Achberger M, Herr R, Helmchen H, Benkert O. [Psychiatric diseases and their treatment in general practice in Germany. Results of a World Health Organization (WHO) study]. Nervenarzt. 1996;67(3):205-15. German.

19. Goldberg DP, Gater R, Sartorius N, Ustun TB, Piccinelli M, Gureje O, et al. The validity of two versions of the GHQ in the WHO study of mental illness in general health care. Psychol Med. 1997;27(1):191-7, https://doi.org/10.1017/S00 33291796004242.

20. Üstün T, Sartorius N. Mental illness in general health care: An international study. New York: Wiley and Sons; 1995.

21. Meißner-Pöthig D. [Vitality diagnostics according Pöthig]. In: Meißner-Pöthig D, Michalak U, editors. [Vitality and medical intervention. Vitality diagnostics: Basics, offers, consequences]. Stuttgart: Hippokrates; 1997. p. 64-72. German.

22. Meißner-Pöthig D. [Reference case study for vitality diagnostics]. In: Meißner-Pöthig D, Michalak U, editors. [Vitality and medical intervention. Vitality diagnostics: Basics, offers, consequences]. Stuttgart: Hippokrates; 1997. p. 73-113. German.

23. Kotler DP, Burastero S, Wang J, Pierson RN. Prediction of body cell mass, fat-free mass, and total body water with bioelectrical impedance analysis: Effects of race, sex, and disease. Am J Clin Nutr. 1996;64(3 Suppl):489-97.

24. AG Wissenschaft/BIAdata Base Project. [Fat and muscle mass [\%] over the ages 0-100 years] [Internet]. AG Wissenschaft; 2012 [cited 2016 Mar 24]. Available from: http://
www.egofit.de/Tabelle_0-100_Jahre_Fett_und_Muskelmasse.pdf. German.

25. Seibt R. [Interview guideline for case and occupational history of teachers]. Dresden: Publishing company of the Technical University Dresden; 2009. German.

26. Hasselhorn H, Freude G. [The Work Ability Index A guide]. Bremerhaven: Wirtschaftsverlag NW Publisher for New Science GmbH; 2007. German.

27. Cohen J. Statistical power analysis for the behavioral sciences. 2nd ed. Hillsdale: Erlbaum; 1988.

28. Mancia G, Fagard R, Narkiewicz K, Redon J, Zanchetti A, Böhm M, et al. ESH/ESC guidelines for the management of arterial hypertension: The Task Force for the management of arterial hypertension of the European Society of Hypertension (ESH) and of the European Society of Cardiology (ESC). Eur Heart J. 2013;34(28):2159-219, https:// doi.org/10.1093/eurheartj/eht151.

29. World Health Organization. Global recommendations on physical activity for health. Geneva: The Organization; 2010.

30. Al-Fudail M, Mellar H. Investigating teacher stress when using technology. Comput Educ. 2008;51(3):1103-10, https://doi.org/10.1016/j.compedu.2007.11.004.

31. Kyriacou C. Teacher stress: Directions for future research. Educ Rev. 2001;53(1):27-35, https://doi.org/10.10 80/00131910120033628.

32. Kovess-Masféty V, Sevilla-Dedieu C, Rios-Seidel C, Nerrière $\mathrm{E}$, Chan Chee $\mathrm{C}$. Do teachers have more health problems? Results from a French cross-sectional survey. BMC Public Health. 2006;6:101-10, https://doi.org/10.1186/14712458-6-101.

33. Bellingrath S, Weigl T, Kudielka BM. Chronic work stress and exhaustion is associated with higher allostastic load in female school teachers. Stress. 2009;12(1):37-48, https:// doi.org/10.1080/10253890802042041.

34. Rensing L, Koch M, Rippe B, Rippe V. [Man in stress: Psyche, body, molecules]. Munich: Elsevier; 2005. German.

35. Jacobi F, Höfler M, Strehle J, Mack S, Gerschler A, Scholl L, et al. [Mental disorders in the general population: Study on 
the health of adults in Germany and the additional module mental health (DEGS1-MH)]. Nervenarzt. 2014;85(1):7787, https://doi.org/10.1007/s00115-013-3961-y. German.

36. Bauer J, Unterbrink T, Hack A, Pfeifer R, Buhl-Griesshaber V, Müller U, et al. Working conditions, adverse events and mental health problems in a sample of 949 German teachers. Int Arch Occup Environ Health. 2007;80(5): 442-9, https://doi.org/10.1007/s00420-007-0170-7.

37. Goldberg DP, Oldehinkel T, Ormel J. Why GHQ threshold varies from one place to another. Psychol Med. 1998; 28(4):915-21, https://doi.org/10.1017/S0033291798006874.

38. Rehm U, Seibt R, Hardt J, Dizinger V. [Health Report 2008. Teachers of the Saxon Education Agency regional office Chemnitz]. Dresden: Publishing company of the Dresden University of Technology; 2008. German.

39. Landsbergis PA, Dobson M, Koutsouras G, Schnall P. Job strain and ambulatory blood pressure: A meta-analysis and systematic review. Am J Public Health. 2013;103(3):61-71, https://doi.org/10.2105/AJPH.2012.301153.

40. Neuhauser H, Thamm M, Ellert U. [Blood pressure in Germany 2008-2011: Results of the German Health Interview and Examination Survey for Adults (DEGS1)]. Bundesgesundheitsblatt. 2013;56(5-6):795-801, https://doi. org/10.1007/s00103-013-1669-6. German.

41. Mensink GBM, Schienkiewitz A, Haftenberger M, Lampert T, Ziese T, Scheidt-Nave C. [Overweight and obesity in Germany: Results of the German Health Interview and Examination Survey for Adults (DEGS1)]. Bundesgesundheitsblatt. 2013;56(5-6):786-94, https://doi.org/10.1007/s00 103-012-1656-3. German.

42. Krug S, Jordan S, Mensink GBM, Müters S, Finger J, Lampert T. [Physical activity: Results of the German Health Interview and Examination Survey for Adults (DEGS1)]. Bundesgesundheitsblatt. 2013;56(5-6):765-71, https://doi. org/10.1007/s00103-012-1661-6. German.

43. Stangl V, Baumann G, Stangl K. [Cardiovascular risk factors in women]. Dtsch Med Wochenschr. 2003;128(31-32): 1659-64, https://doi.org/10.1055/s-2003-41103. German.
44. Hollmann W, Strüder H. [Sports Medicine: Basics of physical activity, exercise and preventive medicine]. Stuttgart: Schattauer; 2009. German.

45. Fuchs J, Busch M, Lange C, Scheidt-Nave C. Prevalence and patterns of morbidity among adults in Germany. Results of the German telephone health interview survey German Health Update (GEDA) 2009. Bundesgesundheitsblatt. 2012;55(4):576-86, https://doi.org/10.1007/s00103-0121464-9.

46. Iskenius M, Hardt J, Müller B, Hasselhorn H. [Health indicators in an aging workforce. A study on the basis of the BIBB/BAuA survey of 2006]. Arbmed Sozialmed Umweltmed. 2012;47:240-51. German.

47. Kivimäki M, Nyberg ST, Batty GD, Fransson EI, Heikkilä K, Alfredsson L, et al. Job strain as a risk factor for coronary heart disease: A collaborative meta-analysis of individual participant data. Lancet. 2012;380(9852):1491-7, https://doi.org/10.1016/S0140-6736(12)60994-5.

48. Pejtersen JH, Burr H, Hannerz H, Fishta A, Eller NH. Update on work-related psychosocial factors and the development of ischemic heart disease: A systematic review. Cardiol Rev. 2015;23(2):94-8, https://doi.org/10.1097/CRD. 0000000000000033.

49. Krell J, Kutzner C, Härtel S, Bös K. [Daily ailments among healthy, middle-aged adults: Situation report and explanatory approaches]. MMW Fortschr Med. 2011;153 Suppl 3: 101-6. German.

50. Finger JD, Krug S, Gößwald A, Härtel S, Bös K. [Cardiorespiratory fitness among adults in Germany: Results of the German Health Interview and Examination Survey for Adults (DEGS1)]. Bundesgesundheitsblatt. 2013;56(5-6): 772-8, https://doi.org/10.1007/s00103-013-1672-y. German.

51. Fogelholm M. Physical activity, fitness and fatness: Relations to mortality, morbidity and disease risk factors. A systematic review. Obes Rev. 2010;11(3):202-21, https://doi. org/10.1111/j.1467-789X.2009.00653.x.

52. Vogel I, Miksch A, Goetz K, Ose D, Szecsenyi J, Freund T. The impact of perceived social support and sense of 
coherence on health-related quality of life in multimorbid primary care patients. Chronic Illn. 2012;8(4):296-307, https://doi.org/10.1177/1742395312445935.

53. Goldberg DP, Williams P. A user's guide to the General Health Questionnaire. Windsor: NFER-Nelson; 1998.

54. Thomas O, Shipman KE, Day K, Thomas M, Martin U, Dasgupta I. Prevalence and determinants of white coat effect in a large UK hypertension clinic population. J Hum Hypertens. 2016;30(6):386-91, https://doi.org/10.1038/jhh.2015.95. 55. Unterbrink T, Zimmermann L, Pfeifer R, Rose U, Joos A, Hartmann A, et al. Improvement in school teachers' mental health by a manual-based psychological group program. Psychother Psychsom. 2010;79(4):262-4, https://doi.org/10. 1159/000315133.

This work is available in Open Access model and licensed under a Creative Commons Attribution-NonCommercial 3.0 Poland License - http://creativecommons.org/ licenses/by-nc/3.0/pl/deed.en. 